Original article

\title{
The straits of Gibraltar and Kara Gates: a comparison of internal tides
}

\section{Les détroits de Gibraltar et de Kara Gates : comparaison des ondes internes}

\author{
Eugene G. Morozov ${ }^{a}$, Gregorio Parrilla-Barrera ${ }^{\text {b,*, }}$ \\ Manuel G. Velarde ${ }^{c, 1}$, Anatoly D. Scherbinin ${ }^{a}$ \\ ${ }^{a}$ Shirshov Institute of Oceanology, Russian Academy of Sciences, Nakhimovsky prospekt 36, 117851 Moscow, Russia \\ ${ }^{b}$ Instituto Español de Oceanografía, Corazón de María 8, 28002 Madrid, Spain \\ ${ }^{c}$ Instituto Pluridisciplinar, Paseo Juan XXIII no. 1, 28040 Madrid, Spain
}

\begin{abstract}
Moored current measurements, numerical model calculations, and satellite images from the straits of Gibraltar and Kara Gates are compared. The vertical internal displacements (double amplitudes) with a semidiurnal frequency are extremely large in both straits. The displacements are related to internal tidal waves over the sills. The energy of the internal tides is transferred to an internal bore and associated wave packets of short-period internal waves. Their surface manifestation can be seen on the satellite images. Numerical modeling shows that the outflowing current from the Mediterranean Sea to the Atlantic Ocean has a significant influence on internal tides. In the Kara Gates, the flow from the Barents Sea to Kara Sea has a similar influence. The internal tide propagating in the opposite direction to the flows intensifies and breaks down into shorter period waves that are seen on the satellite images in the eastern part of the Strait of Gibraltar and in the southwestern part of the Kara Gates.
\end{abstract}

(C) 2003 Éditions scientifiques et médicales Elsevier SAS and Ifremer/CNRS/IRD. All rights reserved.

\section{Résumé}

Nous présentons les comparaisons sur les mesures de courants effectués à partir de bouées, les calculs de modéles numériques, et les images de satellites sur les détroits de Gibraltar et de Kara Gates. Les déplacements internes verticaux (double amplitude) avec une fréquence semi-diurne sont extrêmement grands dans les deux détroits. Les déplacements sont liés à des ondes de marée interne sur les seuils. L'énergie des ondes de marée interne est transférée à un front interne et à des paquets associés à des ondes de période plus courte. Leur manifestation en surface peut être vue a partir d'images satellite. Les modéles numériques montrent que le courant inférieur de la Méditerranée vers l'Atlantique a une influence significative sur les marées internes. Dans le Kara Gates le courant de la mer de Barents vers la mer de Kara a une influence similaire. La marée interne qui se propage dans le sens inverse du courant se décompose en ondes de plus courte période qui sont observables sur les images satellite dans la partie est du détroit de Gibraltar et dans la partie sud-est du Kara Gates.

(C) 2003 Éditions scientifiques et médicales Elsevier SAS and Ifremer/CNRS/IRD. All rights reserved.

Keywords: Internal tide; Remote sensing; Strait of Gibraltar; Kara Sea

Mots clés : Marée interne ; Télédétection ; Détroit de Gibraltar ; Mer de Kara

\section{Introduction}

The Strait of Gibraltar (Fig. 1) is located in the southwestern extreme of Europe, whereas the Strait of Kara Gates

\footnotetext{
* Corresponding author.

E-mail address: gregorio.parilla@md.ieo.es (G. Parrilla-Barrera).

${ }^{1}$ Also at International Center for Mechanical Sciences (CISM), Palazzo del Torso, Piazza Garibaldi, 33100 Udine, Italy
}

(Fig. 2) is located in its northeastern part. The latter strait is also called Kara Strait or Karskiye Vorota.

A two-layer system of opposite flows exists in the Strait of Gibraltar. The upper inflowing current from the Atlantic Ocean compensates for the water deficit in the Mediterranean Sea. It is forced by the pressure gradient from the sea level differences caused by the excess of evaporation in the Mediterranean basin over the precipitation and freshwater discharge of the rivers. The pressure gradient owing to the higher density of the deep Mediterranean waters forces the 


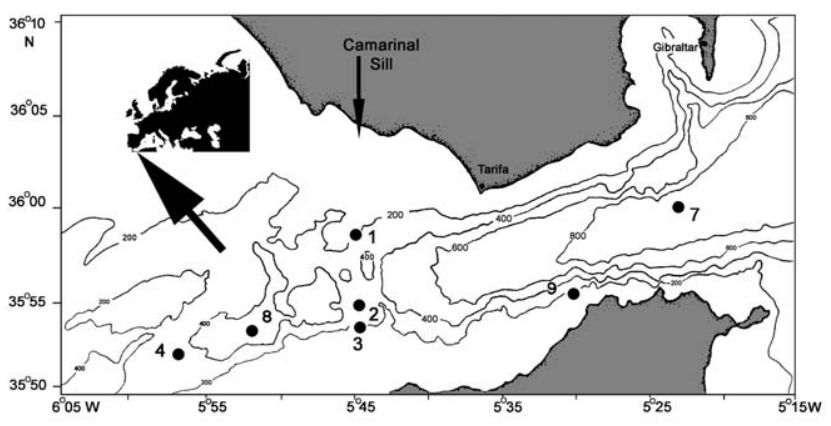

Fig. 1. Gibraltar Strait and moorings location during the Gibraltar experiment in 1985-1986. The 200, 400, 600 and 800-m depth isobaths are shown.

lower outflowing high salinity current to the Atlantic Ocean maintaining the salt balance in the sea. A barotropic tidal wave is imposed on this system with velocities in the range of $70-80 \mathrm{~cm} \mathrm{~s}^{-1}$ directed predominantly along the axis of the strait forming an unsteady flow. The tidal currents flowing over uneven topography in the strait generate an internal wave of high amplitude. Lacombe and Richez (1982), Bryden et al. (1994), and Morozov et al. (2002), have reviewed the historical data and new concepts about the exchange and internal waves in the Strait of Gibraltar.

The flow of the Atlantic waters into the Mediterranean Sea according to Bryden et al. (1994) is equal to $0.72 \mathrm{~Sv}$ $\left(10^{6} \mathrm{~m}^{3} \mathrm{~s}^{-1}\right)$ while the Mediterranean outflow is equal to $-0.68 \mathrm{~Sv}\left(1 \mathrm{~Sv}=10^{6} \mathrm{~m}^{3} \mathrm{~s}^{-1}\right)$. The difference in the transport balances the evaporation in the Mediterranean Sea, which is approximately $52 \mathrm{~cm}$ of the sea level per year.

A rapid deepening of the interface in-phase with the tide occurs every $12 \mathrm{~h}$ west of Camarinal Sill in the Strait of Gibraltar. It is followed by an eastward acceleration of the upper layer flow, which produces an internal bore. The interface deepens more than $200 \mathrm{~m}$ in $1 \mathrm{~h}$ and the surface currents increase by $1 \mathrm{~m} \mathrm{~s}^{-1}$ (Armi and Farmer, 1988). The eastward propagation of the internal bore is accompanied by a series of surface "slicks" also propagating eastward with a speed of about $1.5 \mathrm{~m} / \mathrm{s}$. In the western part of the Strait of Gibraltar this phenomenon is almost not manifested.

Many papers report observations from various types of data about wave packets propagating in the eastern part of the strait. The surface slicks formed by these waves are clearly

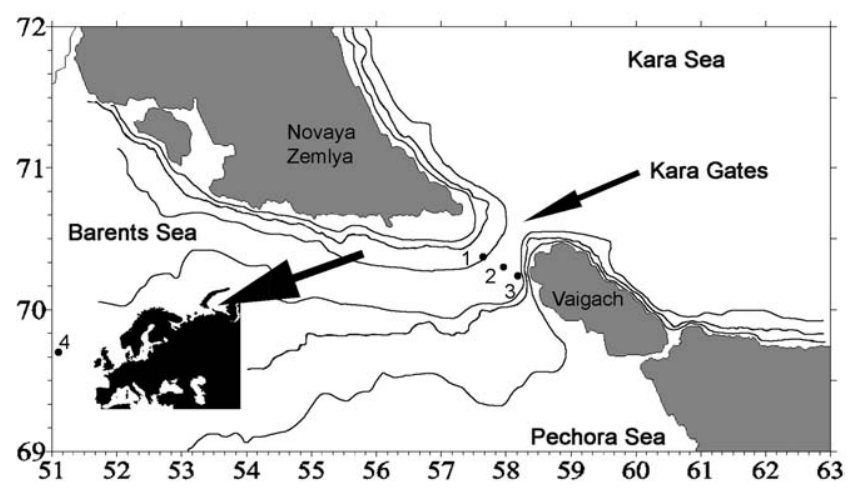

Fig. 2. Position of moorings in the Kara Gates. The 25, 50 and 100-m depth isobaths are shown. seen in a photograph from space (Oceanography from the Space Shuttle, 1989). These packets are observed almost each tidal cycle. Watson (1994) gives a summary of the properties of these waves reported in about 20 papers. The period of the waves is around 10-20 min, the packet width is about $10-15 \mathrm{~km}$, its duration is several hours, and the wavelength in the packet varies from 0.5 to $2.5 \mathrm{~km}$.

The Strait of Kara Gates (Fig. 2) connects the Barents and Kara seas in the Arctic Ocean. The Barents Sea is a relatively warm sea because the current system of the Gulf Stream, North Atlantic current and Norwegian current brings warm water into it, and although the southern part of the sea is located at $67-68^{\circ} \mathrm{N}$ latitudes, it usually does not freeze in winter. The Kara Sea is an ice-cold sea. The ice cover in the southern part of the sea disappears only for a couple of months in summer. Due to the density difference, a surface flow exists from the Barents Sea to the Kara Sea. A flow of dense waters in the opposite direction was observed for the first time by A.D. Scherbinin (the details are presented below) in the deep channel in the southeastern part of the strait. An opposite seasonal surface flow from the Kara Sea in the northern part of the Kara Gates, which is mainly wind driven, initiates the Litke current southwest of Novaya Zemlya. This current exists at shallow depths only near the coast. These two flows are significantly less intense than the main flow from the Barents Sea (McClimans et al., 2000).

Harms and Karcher (1999) indicate that the inflow of warm water from the Barents Sea is enhanced in winter. The maximum transport rate into the Kara Sea is $0.65 \mathrm{~Sv}$. In summer, the northerly winds prevail and reduce the inflow. The yearly averaged inflow is 0.3 Sv. Johnson et al. (1997) studied the water masses and currents in the central part of the Kara Sea focusing on the river freshwater transport. Pavlov and Pfirman (1995) analyze measurements of internal waves in the Kara Sea, indicating that internal waves with tidal frequencies are observed in the Kara Sea in summer. Their amplitudes are up to $12 \mathrm{~m}$ and the wavelength is several tens of kilometers. McClimans et al. (2000) studied the transport processes in the Kara Sea using field hydrographic data and a laboratory model, giving a general circulation scheme on the basis of the most recent measurements.

We do not possess any reliable historical oceanographic field measurements of short-period internal waves in the Kara Gates since the region has been poorly investigated. In addition, the weather and ice conditions are very severe. In 1997, three moorings were deployed in the Kara Gates which allowed us to make the first study of internal waves in this region. We also have satellite images of the sea surface.

In this paper, we compare hydrodynamic and oceanographic conditions in the two straits which although geographically located in different parts of Europe, have many similar features in their dynamics. The objective addressed in this paper is to show extreme internal tidal waves in the two straits, where the vertical oscillations occupy almost the entire depth, and to compare the parameters of internal tide on the basis of moored measurements and numerical calcu- 
Table 1

Position of moorings in the Strait of Gibraltar used in the analysis

\begin{tabular}{lllll}
\hline Mooring number & \multicolumn{2}{l}{ Coordinates } & \multicolumn{2}{l}{ Time of measurements (GMT) } \\
\cline { 2 - 5 } & Northern latitude & Western longitude & Start & End \\
\hline 1 & $35^{\circ} 58.26^{\prime}$ & $5^{\circ} 44.64^{\prime}$ & $22.10 .198515: 00$ & $04.05 .198616: 00$ \\
2 & $35^{\circ} 54.78^{\prime}$ & $5^{\circ} 44.40^{\prime}$ & $22.10 .198512: 30$ & $13.10 .198613: 00$ \\
3 & $35^{\circ} 53.40^{\prime}$ & $5^{\circ} 44.22^{\prime}$ & $21.10 .198518: 00$ & $21.04 .198608: 00$ \\
4 & $35^{\circ} 52.02^{\prime}$ & $5^{\circ} 57.06^{\prime}$ & $17.10 .198518: 00$ & $13.10 .198607: 00$ \\
7 & $36^{\circ} 00.00^{\prime}$ & $5^{\circ} 22.74^{\prime}$ & $19.10 .198515: 30$ & $27.03 .198607: 00$ \\
8 & $35^{\circ} 53.16^{\prime}$ & $5^{\circ} 50.58^{\prime}$ & $17.10 .198516: 30$ & $26.02 .198614: 00$ \\
9 & $35^{\circ} 55.26^{\prime}$ & $5^{\circ} 30.00^{\prime}$ & $28.05 .198612: 00$ & $13.10 .198616: 00$ \\
\hline
\end{tabular}

lations. We also correlate the surface manifestation of the internal tide with the dominating currents in the straits.

Internal tides are very important in the dynamics of the straits. Their generation occurs on the steep slopes of sills, which cross the straits, as well as at the shelf edges (Hibia, 1990). Much research has been done recently at shelf edges, which can be important for the understanding of internal tide dynamics (Xing and Davies, 1998; Jeans and Sherwin, 2001).

\section{Moorings in the Strait of Gibraltar and Kara Gates}

\subsection{Strait of Gibraltar}

The position of the moorings set in the Strait of Gibraltar during the 1985-1986 Gibraltar experiment is shown in Fig. 1 (Kinder and Bryden, 1987). The moorings were in operation from October 1985 to October 1986. The coordinates of the moorings are given in Table 1 . Three moorings $(1,2,3)$ were located over Camarinal Sill.

We used the data from mooring 2 in June 1986 to plot the displacements of the isotherms. Current meters were located at the depths of $91,112,135,182,235$ and $302 \mathrm{~m}$. The instruments measured velocity, temperature, pressure and conductivity. Strong tidal currents induced vertical motion of the mooring's buoyancy so that all instruments were subject to large vertical displacements. The vertical displacement of the upper instrument ranged from 91 to $170 \mathrm{~m}$. The instrument initially set at $112 \mathrm{~m}$ could deepen to $186 \mathrm{~m}$. The pressure sensors recorded the actual location of the instruments and allowed us to trace the real location of the isotherms by interpolating the values of temperature to the fixed levels of depth. The interpolation of the locations of isotherms was carried out onto a grid with a $10-\mathrm{m}$ depth interval and 30-min sampling interval. The displacement of $13.0^{\circ} \mathrm{C}$ isotherm for $220 \mathrm{~h}$ from 20 to 30 June, 1985 is shown in Fig. 3 . It gives a good illustration of the internal motion. The displacement of the $13.0{ }^{\circ} \mathrm{C}$ isotherm ranges approximately from 100 to $300 \mathrm{~m}$ (Fig. 3).

Two harmonics are clearly discernible on the plot: diurnal and semidiurnal. A band filter was used to separate different tidal components over the sill in the time series of the $13{ }^{\circ} \mathrm{C}$ isotherm depth (Parks and Burrus, 1987; Morozov et al., 2002).
To isolate the fluctuations with M2 frequency, we provided a frequency band between $1 / 12.37$ and $1 / 12.47 \mathrm{~h}^{-1}$ tuned to a frequency of $1 / 12.42 \mathrm{~h}^{-1}$. The M2 internal tide $(12.42 \mathrm{~h})$ makes the greatest contribution to the total oscillations. Its mean amplitude is equal to $69 \mathrm{~m}$. To isolate the fluctuations with $\mathrm{S} 2$ frequency we provided a frequency band between $1 / 11.95$ and $1 / 12.05 \mathrm{~h}^{-1}$ tuned to a frequency of $1 / 12.00 \mathrm{~h}^{-1}$. The amplitude of the $\mathrm{S} 2(12.0 \mathrm{~h})$ component is $12.7 \mathrm{~m}$.

The amplitudes of internal tide at Camarinal Sill are large because this is the region of their generation over the slopes of the bottom topography, over which the currents of the barotropic tide force the internal oscillations. The estimates of the amplitude of vertical displacements with a semidiurnal period at positions of buoys 4, 8, 9 and 7 are 3-4 times smaller than near Camarinal Sill.

\subsection{Kara Gates}

Four moorings were set for a few days in SeptemberOctober, 1997 in the Kara Gates Strait and four hydrographic sections were taken with an NBIS Mark-III CTD in the adjacent region. The coordinates and time of mooring operation are summarized inTable 2 and positions of moorings are shown in Fig. 2. Time sampling was equal to $15 \mathrm{~min}$.

The thermohaline water structure in the strait is formed by cold and saline waters in the shallow coastal zone near the Novaya Zemlya Islands in the northwest and relatively warm and freshened water in the region near Vaigach Island in the southeast, which is influenced by the waters discharged from

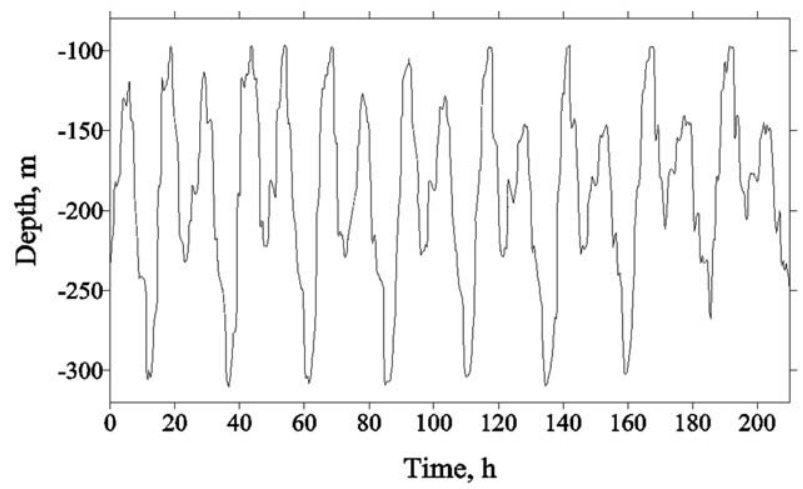

Fig. 3. Vertical displacement of isotherm $13.0^{\circ} \mathrm{C}$ at mooring 2 in the Strait of Gibraltar from 20 to 30 June, 1986. 
Table 2

Position of moorings in the Kara Gates Strait

\begin{tabular}{lllll}
\hline \multirow{2}{*}{ Mooring number } & \multicolumn{2}{l}{ Coordinates } & \multicolumn{3}{l}{ Time of measurements (GMT) } \\
\cline { 2 - 5 } & Northern latitude & Eastern longitude & Start & \multicolumn{2}{l}{ End } \\
\hline 1 & $70^{\circ} 22^{\prime}$ & $57^{\circ} 38^{\prime}$ & $29.09 .199713: 45$ & $03.10 .199709: 45$ \\
2 & $70^{\circ} 18^{\prime}$ & $57^{\circ} 58^{\prime}$ & $29.09 .199718: 00$ & $03.10 .199712: 15$ \\
3 & $70^{\circ} 17^{\prime}$, & $58^{\circ} 11^{\prime}$ & $04.10 .199722: 15$ & $07.10 .199714: 00$ \\
4 & $69^{\circ} 43^{\prime}$ & $51^{\circ} 02^{\prime}$ & $12.08 .199817: 15$ & $30.08 .199802: 45$ \\
\hline
\end{tabular}

the Pechora River to the shallow water Pechora Sea, southwest of the strait. The upper 20-m layer is freshened by melting ice in the region adjacent to the strait from the Kara Sea.

The instruments at 20 and $67 \mathrm{~m}$ on mooring 1, the closest to the Novaya Zemlya Islands, recorded low mean currents of the flow directed to the Kara Sea with a velocity of about $6 \mathrm{~cm} \mathrm{~s}^{-1}$. The tidal component was greater than the mean currents; therefore, reversing flow was periodically observed. In the middle of the strait, mooring 2 recorded a stable water transport from the Barents Sea with a velocity of 18 and $6 \mathrm{~cm} \mathrm{~s}^{-1}$ at depths of 90 and $175 \mathrm{~m}$, respectively. The maximum velocity was equal to $35 \mathrm{~cm} \mathrm{~s}^{-1}$. The tidal currents either intensified or diminished the mean current. The measurements on mooring 3 set in the southeastern part of the strait near Vaigach Island at the maximum depth in the strait $(230 \mathrm{~m})$ allowed us to observe the bottom flow from the Kara Sea. The upper instrument at $65 \mathrm{~m}$ recorded the highest northeasterly currents with velocities exceeding $50 \mathrm{~cm} \mathrm{~s}^{-1}$. The mean velocity was equal to $26.5 \mathrm{~cm} \mathrm{~s}^{-1}$. The currents calculated from the density profile across the strait were close to $80 \mathrm{~cm} \mathrm{~s}^{-1}$ at the surface. At $115 \mathrm{~m}$, the mean northeasterly current was equal to $10.6 \mathrm{~cm} \mathrm{~s}^{-1}$. Between 115 and $215 \mathrm{~m}$, the currents changed their direction to the Barents Sea. The mean velocity of the flow from the Kara Sea measured at $215 \mathrm{~m}$ in the deep channel was equal to $11.2 \mathrm{~cm} \mathrm{~s}^{-1}$. The maximum velocity of the bottom current from the Kara Sea recorded during this period was $43 \mathrm{~cm} \mathrm{~s}^{-1}$.

Of course, we do not claim that moored measurements during several days yield the general results of the circulation in the strait. It is only an episode, which is an example of the summer circulation.

Temperature time series indicate that temperature fluctuations in the strait are very strong. A temperature time series measured at $115 \mathrm{~m}$ on mooring 3 is shown in Fig. 4. We used a band filter to separate the component of the temperature fluctuations with the M2 period (12.42 h). The time series with 15-min sampling interval were band filtered using the elliptic filter of the second order (Parks and Burrus, 1987). To isolate the fluctuations with M2 frequency, we provided a frequency band between $1 / 12.37$ and $1 / 12.47 \mathrm{~h}^{-1}$ tuned to a frequency of $1 / 12.42 \mathrm{~h}^{-1}$. This filter can separate a narrow band of fluctuations without significant errors. The data at the start and end of the time series are not cut off, which is extremely important for such short time series. The same temperature time series after band filtering is shown in the upper part of Fig. 4. Temperature fluctuations with the M2 period reach $0.25^{\circ} \mathrm{C}$.
Mooring 3 had three instruments and we used these data to plot the displacements of isotherms. The instruments located at depths 65,115 and 215 m measured currents and temperature with a 15-min interval. The interpolation of the locations of isotherms was carried out onto a grid with a 5-m depth interval and 15-min sampling interval. The displacement of the $-0.4{ }^{\circ} \mathrm{C}$ isotherm for $64 \mathrm{~h}$ from 4 to 7 October, 1997 is shown in Fig. 5. It gives a good illustration of internal motion. The displacement of the $-0.4{ }^{\circ} \mathrm{C}$ isotherm ranges approximately from 110 to $170 \mathrm{~m}$. This is an enormous span of oscillations with respect to the maximum sea bottom depth $(230 \mathrm{~m})$ in the narrow channel. The average surrounding depths in the region are equal to $120-160 \mathrm{~m}$. The most intensive vertical motion occurs not in the upper layer but in the lower part of the water column. We interpret this as a forced motion due to the influence of the barotropic tide

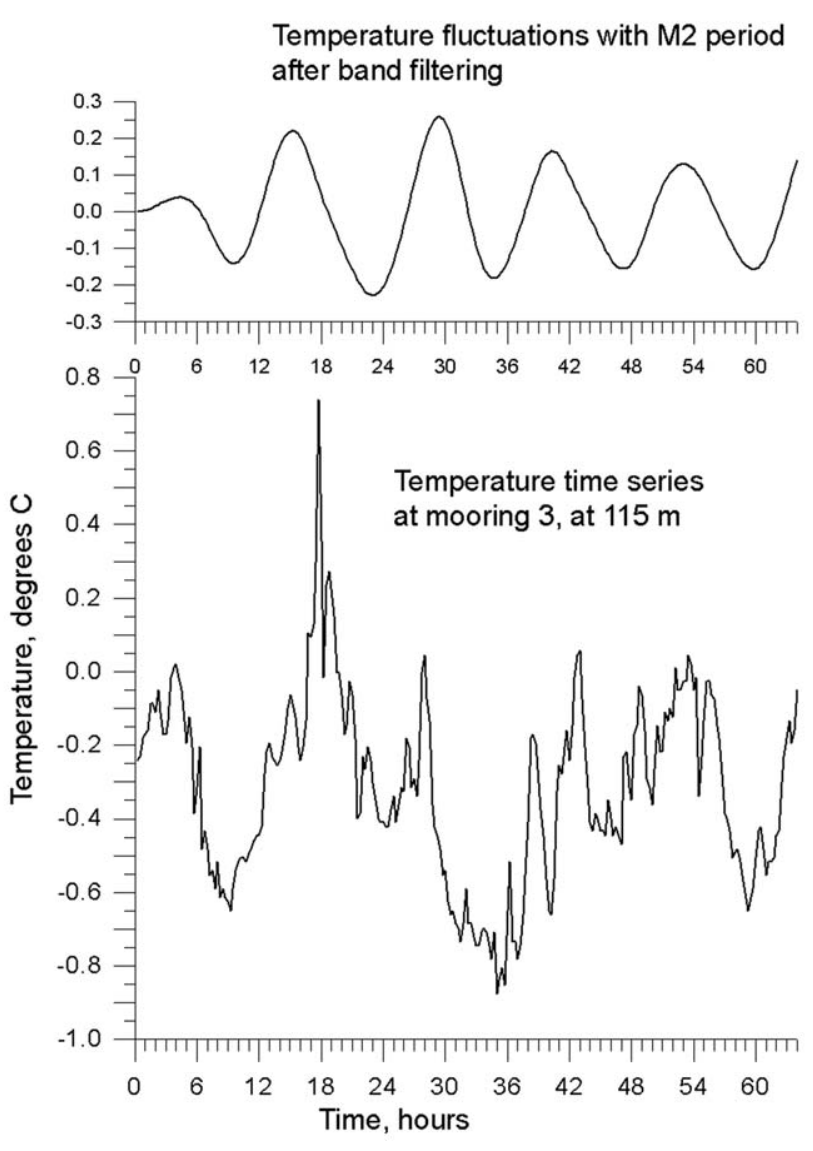

Fig. 4. Temperature time series at $115 \mathrm{~m}$ on mooring 3 in the Kara Gates (lower panel). Band filtered time series to separate the fluctuations with M2 period are shown in the upper panel. 


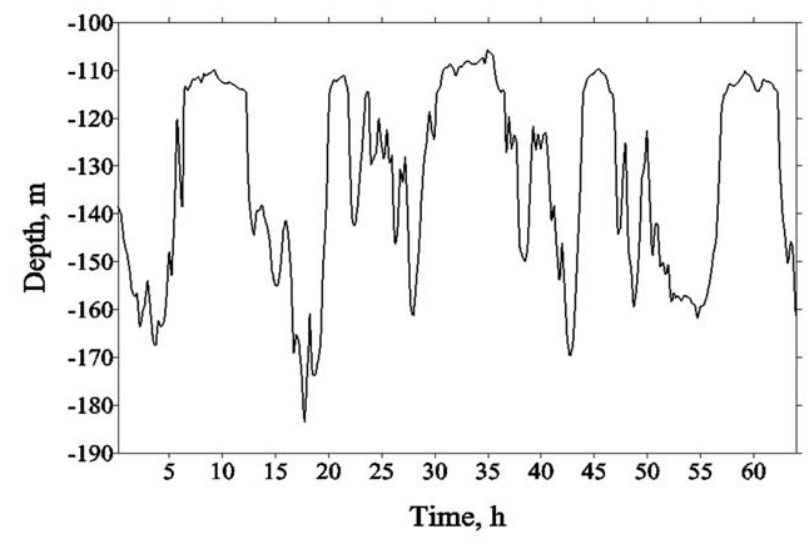

Fig. 5. Vertical displacement of the $-0.4{ }^{\circ} \mathrm{C}$ isotherm at mooring 3 in the Kara Gates.

currents (depth averaged currents) flowing over steep bottom topography.

In order to determine the velocity of the barotropic tide currents, we used a band pass filter to separate the component with a 12.4-h period. The ellipse of the M2 tidal currents obtained at mooring 3 is outlined in Fig. 6 with a thick line. The amplitude of the barotropic tide current according to these calculations was equal to $19 \mathrm{~cm} \mathrm{~s}^{-1}$. This is in good agreement with the calculation of tides, which was carried out by S. Erofeeva in the Oregon State University (USA) using the Topex/Poseidon data (personal communication). The maximum velocity of the barotropic tide on 1 October, 1997 calculated from the satellite data of surface elevations was equal to $19.5 \mathrm{~cm} \mathrm{~s}^{-1}$. The direction of the main tidal axis in both cases was normal to the sill.

In the Kara Strait, there is a high risk of losing the surface moorings due to the floating ice so that they could not be kept for a longer time. Mooring 4 was deployed $200 \mathrm{~km}$ southwest of the strait in the ice-free region. This allowed us to keep the mooring operating for $18 \mathrm{~d}$. The spectrum of temperature fluctuations measured at this station is shown in Fig. 7 (instrument depth $40 \mathrm{~m}$, sea bottom depth $80 \mathrm{~m}$ ). The spectrum is characterized by one reliable peak at a frequency of the semidiurnal tide. Diurnal oscillations are not significant. Band filtering of fluctuations to separate the component with the M2 period showed that the amplitude of vertical displacements in this region is five times smaller than in the strait. Therefore, the amplitude of the wave decreased at least five times in the course of its propagation over a distance of $200 \mathrm{~km}$. If we take into account that other sources of internal tide generation in the region could also contribute to the wave amplitude, the actual decrease of the amplitude could be even greater.

\section{Internal tide wavelength estimates on the basis of the dispersion relation}

We estimated the wavelength of the internal tide from the dispersion relation. We assumed that the bottom is flat be-

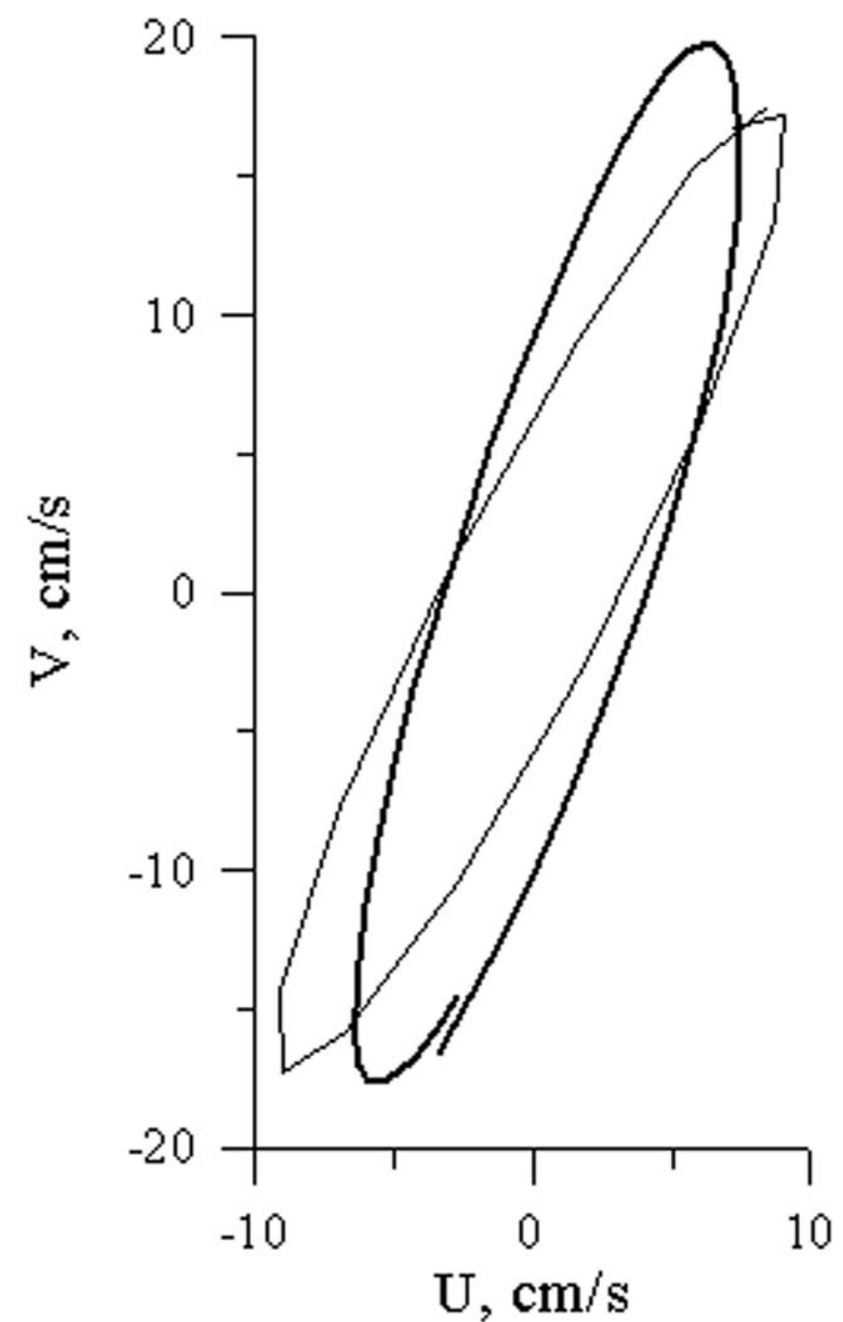

Fig. 6. Ellipse of tidal currents at the M2 frequency on mooring 3 calculated from the measurements is outlined with a thick line. Ellipse of tidal currents calculated on the basis of the Topex/Poseidon data is shown with a thin line.

yond the generation region and no forcing exists beyond the slopes of the sill. To a first approximation, we can estimate the wave-length of internal tide by numerical integration of the equation for vertical velocity $(w)$ induced by internal waves:

$$
\frac{d^{2} w}{d z^{2}}+\frac{N^{2}(z)}{g} \frac{d w}{d z}+\frac{N^{2}(z)-\omega^{2}}{\omega^{2}-f^{2}} w k^{2}=0
$$

where $N^{2}(z)$ is the Brunt-Väisälä frequency based on CTD data east and west of the sill; $\omega$ is the semidiurnal frequency; $f$ is the Coriolis parameter, and $k$ is the horizontal wave number. Vertical velocity at the surface and bottom is zero. This is an eigenvalue problem with depth-dependent BruntVäisälä frequency. We integrated this equation with a vertical step of $10 \mathrm{~m}$ for typical stratification in both straits. The wave numbers obtained in the solution correspond to the modes of internal tides. Mode 1 has no zero crossings (only zero values at the bottom and surface), mode 2 has one zero crossing, etc. The water density used in the calculations in both regions is given in Table 3. 


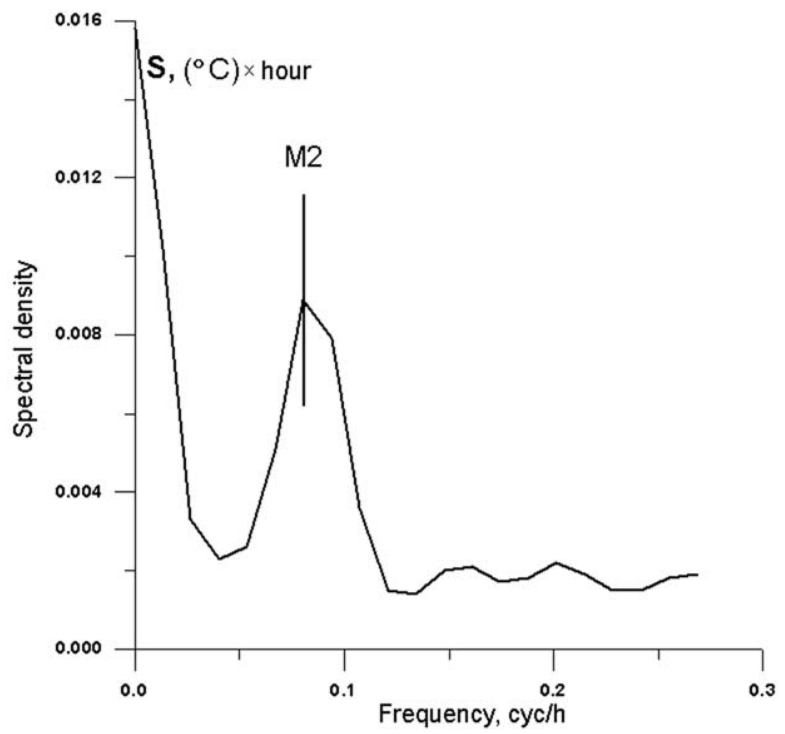

Fig. 7. Spectrum of temperature fluctuations, measured at $40 \mathrm{~m}$ depth on mooring 4. The depth of the sea is $80 \mathrm{~m}$.

\subsection{Strait of Gibraltar}

We assumed that the mean depth east of the sill is $800 \mathrm{~m}$, and west of the sill is equal to $450 \mathrm{~m}$. The calculated wavelength of the semidiurnal internal tide (mode 1) east of the sill was $94 \mathrm{~km}$ (phase velocity $2.1 \mathrm{~m} \mathrm{~s}^{-1}$ ), and west of the sill the wavelength was $60 \mathrm{~km}$ (phase velocity $1.34 \mathrm{~m} \mathrm{~s}^{-1}$ ).

\subsection{Kara Gates}

The mean depth in the region was assumed to be $160 \mathrm{~m}$. The calculated wavelength of the semidiurnal internal tide (mode 1) was $48 \mathrm{~km}$ (phase velocity $1.05 \mathrm{~m} \mathrm{~s}^{-1}$ ). This result corresponds to the case of zero mean current. A vertically uniform current of $19 \mathrm{~cm} \mathrm{~s}^{-1}$ directed opposite to the wave decreases the wavelength by $3 \mathrm{~km}$ and increases it approxi-
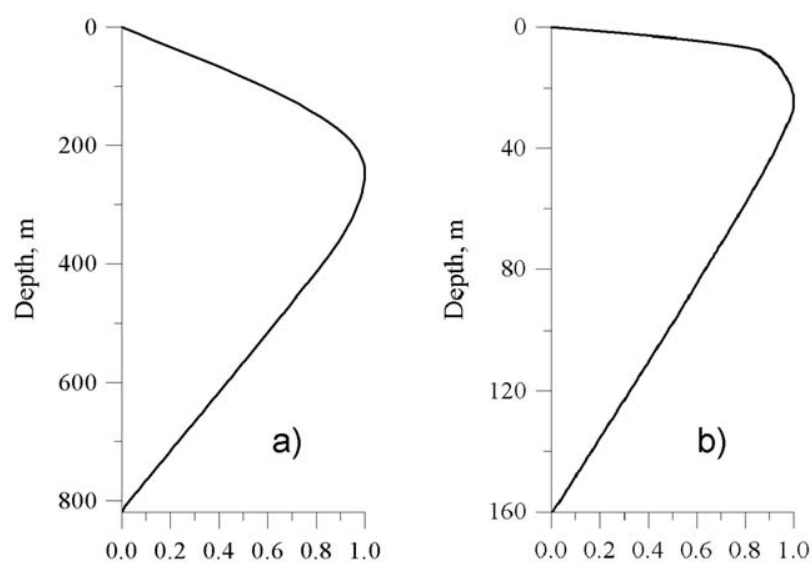

Fig. 8. Vertical displacement induced by internal tide (first mode) normalized by the maximum value. (a) Strait of Gibraltar; (b) Kara Gates.

mately by the same amount when it flows in the same directions. Such surprisingly long wavelength for the Kara Gates region is explained by the proximity of the region to the critical latitudes, where the M2 period becomes very close to the inertial period. Due to a small denominator, the coefficient in the third term of Eq. (1) becomes large, which should be compensated by decreasing of wavenumber $k$. At latitudes close to $74.5^{\circ} \mathrm{N}$, the inertial period becomes equal to the $\mathrm{M} 2$ period; hence, $k$ turns to zero, and the wavelength grows to infinity. In this case, Eq. (1) has a singularity and requires special methods for solution. The corresponding physical processes are analyzed by Furevik and Foldvik (1996) and Robertson (2001). The summer stratification used in the calculation is very strong: the upper layer temperature reached $7{ }^{\circ} \mathrm{C}$ while the temperature in the lower layers was below zero.

The normalized vertical displacements induced by the internal tides of the first mode calculated for the two straits are shown in Fig. 8. The eigen functions differ because the stratification in the Kara Gates is stronger than that in the

Table 3

Vertical distribution of density in the straits used in the calculations

\begin{tabular}{|c|c|c|c|c|}
\hline \multicolumn{3}{|c|}{ Strait of Gibraltar } & \multicolumn{2}{|l|}{ Kara Gates } \\
\hline \multirow[t]{2}{*}{ Depth (m) } & \multicolumn{2}{|l|}{ Density } & \multirow[t]{2}{*}{ Depth (m) } & \multirow[t]{2}{*}{ Density } \\
\hline & Western part & Eastern part & & \\
\hline 0 & 1.02500 & 1.025000 & 0 & 1.025000 \\
\hline 0 & 1.02504 & 1.025700 & 10 & 1.025200 \\
\hline 20 & 1.02508 & 1.026000 & 20 & 1.027900 \\
\hline 30 & 1.02512 & 1.026320 & 30 & 1.028600 \\
\hline 50 & 1.02521 & 1.026620 & 50 & 1.029100 \\
\hline 00 & 1.02552 & 1.027600 & 75 & 1.029080 \\
\hline 150 & 1.02620 & 1.028150 & 100 & 1.029124 \\
\hline 200 & 1.02670 & 1.028450 & 120 & 1.029148 \\
\hline 250 & 1.02710 & 1.028620 & 140 & 1.029170 \\
\hline 300 & 1.02755 & 1.028800 & 160 & 1.029190 \\
\hline 400 & 1.02788 & 1.029040 & & \\
\hline 500 & 1.02796 & 1.029085 & & \\
\hline 700 & & 1.029095 & & \\
\hline 800 & & 1.029100 & & \\
\hline
\end{tabular}


Strait of Gibraltar. The density difference between the surface and bottom in the Kara Strait is equal to 0.004 (1.0029 $\left.1.0025=0.004 \mathrm{~g} \mathrm{~cm}^{3} \mathrm{~s}^{-1}\right)$, whereas in the Strait of Gibraltar, this difference is $0.003\left(1.0028-1.0025=0.003 \mathrm{~g} \mathrm{~cm}^{3} \mathrm{~s}^{-1}\right)$. The Strait of Gibraltar is 5-6 times deeper than the Kara Gates. In the Kara Gates, the seasonal interface is very shallow and a thin warm layer near the surface forms a very sharp and shallow thermocline.

\section{Numerical model calculations}

Numerical modeling was performed to study the influence of the currents in the straits on the dynamics of internal motion. The model allows us to obtain a pattern of the internal wave motion generated over the slopes of the sill due to the barotropic tide currents inducing vertical motion of isopycnals. At the same time, the numerical model also allows us to analyze the evolution of the internal tide in the course of its propagation away from the region of generation and study the properties of the wave.

Most of the numerical models describe the generation of internal tides over the sill in terms of the interface displacement (Longo et al, 1992; Brandt et al, 1996; Harms and Karcher, 1999). Wang (1993) used a model for continuous stratification, but the resolution of the model is not enough to analyze the propagation of short-period wave packets. Reducing the internal motion only to the displacement of the interface is not enough to analyze internal tidal waves in the entire water column, in particular, to analyze their nearsurface properties that influence their surface manifestation. We use a fully non-hydrostatic model developed by Vlasenko (Morozov et al., 2002; Vlasenko and Hutter, 2002) with continuous stratification, which gives us the possibility to analyze the generation of internal waves over bottom topography and their propagation and evolution. In the calculation, in the Strait of Gibraltar, we introduced two harmonics of the barotropic tide: semidiurnal and diurnal, for a better simulation of the real processes.

We consider a two dimensional $(x, z)$ flow in a continuously stratified rotating ocean of variable depth. Internal waves are described by the following set of equations:

$\Omega_{t}+J(\Omega, \Psi)-f V_{z}=\frac{g \rho_{x}}{\rho_{0}}+K(x) \Omega_{x x}+K \Omega_{z z}+\left(K \Psi_{z z}\right)_{z}$

$V_{t}+J(V, \Psi)+f \Psi_{z}=K(x) V_{x x}+\left(K V_{z}\right)_{z}$

$\rho_{t}+J(\rho, \Psi)+\frac{\rho_{0} N^{2}(z)}{g} \Psi_{x}=R(x) \rho_{x x}+\left(R \rho_{z}\right)_{z}+\left(R \rho_{0_{z}}\right)_{z}$

where $\psi$ is the stream function $\left(\Psi_{z}=u ; \Psi_{x}=-w\right), \Omega=\Psi_{x x}+$ $\Psi_{z z}$ is the vorticity, $(U, V, W)$ is the velocity vector, $N$ is the Brunt-Väisälä frequency, $\rho$ is the density disturbance due to the wave motion, $\rho_{0}$ is the mean density, $f$ is the Coriolis parameter, $K, K(x), R$, and $R(x)$ are the vertical and horizontal coefficients of turbulent viscosity and mass diffusivity, respectively, $J$ is the Jacobian and $g$ is the acceleration due to gravity.
The model is two dimensional. However, we introduce the equation for the $\mathrm{V}$-component of velocity normal to the $x, z$ plane to account for the effects of rotation. Here, the $\mathrm{V}$-component varies only in $x, z$ plane and does not change along the transversal $y$-axis.

The boundary conditions at the surface, $z=0$ are:

$$
\rho_{z}=0, \Omega=0, \Psi=0
$$

We assume zero vertical motion and no tangential stresses at the surface.

At the bottom, we assume zero heat and mass transports:

$$
\text { at } z=-H(x), \partial \rho / \partial n=0, \Psi=\Psi_{0} \sin \omega \mathrm{t}
$$

where $\omega$ is the tidal frequency, $n$ denotes the unit normal vector to the bottom and $\Psi_{0}$ is the amplitude of the mass transport in a barotropic tidal current. The boundary condition for vorticity at the bottom is calculated using equation $\Omega=\Delta \Psi$ with the value of the $\Psi$ field obtained at the previous time step.

The wave perturbations of vorticity, stream function, and density are assumed zero at the lateral boundaries located far from the bottom irregularities at the submarine ridge. We stop the calculations when the wave perturbations reach the lateral boundaries. Continuous stratification was specified in each of the 20 layers. The density assumed in the model corresponds to the values given in Table 3. The bottom topography was specified on the basis of navigation charts.

\subsection{Strait of Gibraltar}

We have chosen a domain $400 \mathrm{~km}$ long with a horizontal step of $100 \mathrm{~m}$ and 20 vertical levels. The horizontal size of the domain significantly exceeds the size of the strait, but allows us to analyze the processes in the middle of the domain before the perturbations reach the lateral boundaries. The time step was approximately equal to $7 \mathrm{~s}$. These parameters satisfy the Courant-Friedrichs-Levy condition (Richtmyer, 1957). In the calculations of the wave evolution, we specified the coefficients of horizontal eddy viscosity and density diffusivity as $60 \mathrm{~m}^{2} \mathrm{~s}^{-1}$ over the ridge and $4 \mathrm{~m}^{2} \mathrm{~s}^{-1}$ beyond the ridge over the flat bottom in the model. This choice of the spatial and time steps together with the choice of the coefficients of turbulent viscosity allowed us to make the calculations free from numerical instability caused by the strong non-linearity. The coefficients of vertical turbulent viscosity and density diffusion were set to $0.001 \mathrm{~m}^{2} \mathrm{~s}^{-1}$ over the sill and zero beyond the sill.

In the beginning of the calculations, the Strait of Gibraltar was divided into the western and eastern parts and density stratifications characteristic of these two regions were specified in each of the parts. Next, we set the water to flow free under the influence of different density distributions in the eastern and western parts. After the adjustment and formation of a two-layer flow in the central part of the computational area, we superimposed the tidal flow. Thus, we set up an eastward flow with mean velocities of about $50 \mathrm{~cm} \mathrm{~s}^{-1}$ occupying the upper layer and a lower westward flow with a 


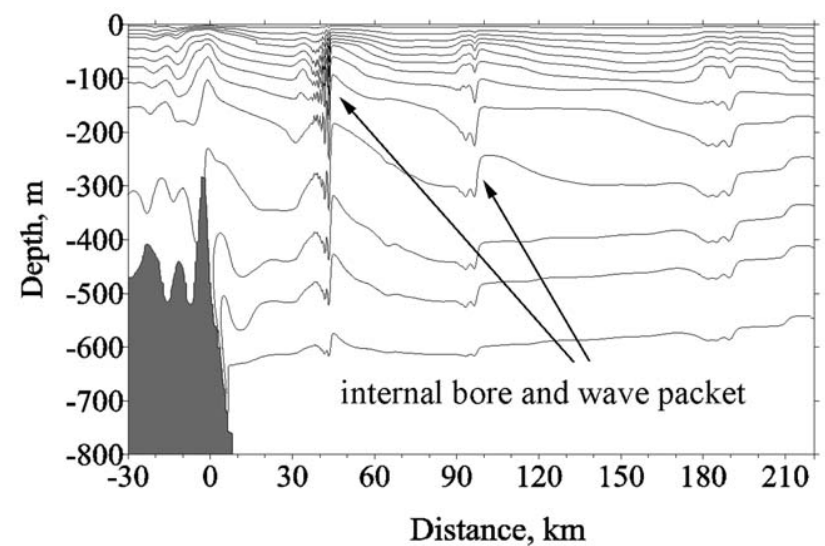

Fig. 9. Numerical calculation of internal waves in the eastern part of the Strait of Gibraltar showing the perturbations of the density field induced by propagating internal tide. The contour lines of density between 25.20 and 28.80 are shown with an interval of 0.4. Additional contour lines of 29.0, 29.04 and 29.08 are shown in the deep layers. Gray colored pattern shows bottom topography.

vertically averaged velocity of $25 \mathrm{~cm} \mathrm{~s}^{-1}$. A strong shear between the currents exists approximately at 150-200 m depth in the western part and at 50-100 $\mathrm{m}$ in the eastern part. We superimpose a periodical barotropic tidal current on the mean current by periodically increasing and decreasing the value of the stream function at the surface, while the value of the stream function at the bottom was specified equal to zero. At the western boundary, the maximum amplitude of the barotropic tidal velocity was $80 \mathrm{~cm} \mathrm{~s}^{-1}$.

The periodical changes in the horizontal flow induced an internal wave propagating in both directions from the sill. The sill is located in the middle of the computational area. The perturbations of the density field induced by the propagating internal tide are shown in Fig. 9. This snapshot of the density field is depicted after five tidal periods of calculation.

The fluctuations of the density field are not symmetrical with respect to the position of the Camarinal Sill. The interaction of the barotropic tide with the bottom topography induces stronger internal tide propagating to the east compared to that propagating to the west. The internal bore is formed on the trailing edge of the wave, which is steeper than the leading edge. Since the amplitudes of the internal wave are greatest at mid-depth of the strait (see Fig. 8), the Mediterranean outflow has a greater influence on the internal tide than the surface Atlantic flow. The mean current opposite to the internal tide makes its wavelength shorter, and hence the slopes become steeper, which leads to wave breaking and formation of a packet of shorter internal waves, which follows the bore.

The structure of the westerly propagating wave is the same except for the fact that the bore and wave train of shorter internal waves are less intense. West of Camarinal Sill, the internal tide propagates in the same direction as the current flowing from the Mediterranean. The current increases the wavelength. The internal bore is significantly less intense and only a weak packet of shorter waves appears.

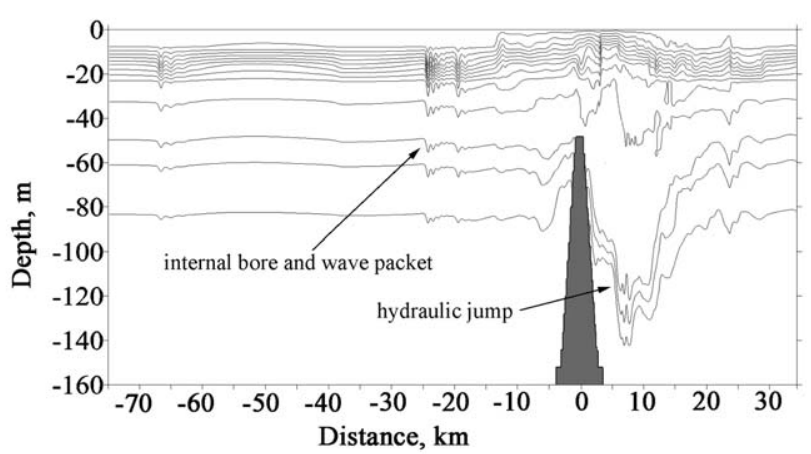

Fig. 10. Numerical calculation of internal waves in the Strait of Kara Gates. The contour lines of density between 25.00 and 29.00 are shown with an interval of 0.4. Additional contour lines of 29.05 and 29.1 are shown in the deep layers. Gray colored pattern shows bottom topography.

The wavelength of the easterly propagating wave is about $92 \mathrm{~km}$. The westerly propagating wave is shorter $(60 \mathrm{~km})$ as the depth west of Camarinal Sill is smaller.

The introduction of two opposite currents with a shear intensifies the internal bore at depths of 100-300 m (Fig. 9). Since in the eastern part of the strait the internal bore and associated wave packet of shorter internal waves are better expressed in the upper layer, their surface manifestation is stronger. This is observed by land based radars, airplanes and satellites (see Section 5).

\subsection{Kara Gates}

We have chosen a domain $150 \mathrm{~km}$ long with a horizontal step of $50 \mathrm{~m}$ and 20 vertical levels. The time step was approximately equal to $2.2 \mathrm{~s}$. We specified the coefficients of horizontal eddy viscosity and density diffusivity as $5 \mathrm{~m}^{2} \mathrm{~s}^{-1}$ over the ridge and $1.2 \mathrm{~m}^{2} \mathrm{~s}^{-1}$ beyond the ridge over the flat bottom in the model. The coefficients are smaller than those in the calculations in the Strait of Gibraltar because the vertical and horizontal steps of the grid are smaller here. Therefore, due to a smaller "numerical viscosity of the scheme", we can use smaller values of coefficients. The coefficients of vertical turbulent viscosity and density diffusion were set to $0.001 \mathrm{~m}^{2} \mathrm{~s}^{-1}$ over the ridge and zero beyond the ridge, same as those in the Strait of Gibraltar. This choice of parameters ruled out numerical instability. A smaller horizontal step in these calculations allows us to increase the non-linearity, which suppresses the dispersion due to stronger rotation at high latitudes.

Since the lower current from the Kara Sea occupies only a thin layer near the bottom in the deepest part of the strait, we introduced in the model calculations only one flow from the Barents Sea, which is directed to the northeast and occupies the entire depth. In the model (Fig. 10), the direction of the flow is from left to right. Its mean velocity was $9 \mathrm{~cm} \mathrm{~s}^{-1}$. As in the Strait of Gibraltar a periodical barotropic tidal flow was superimposed on this current.

Most of the features found in the Strait of Gibraltar are also observed in the Kara Gates. The periodical changes in the tidal horizontal flow induce an internal wave propagating 
Table 4

Wavelengths of semidiurnal internal tides determined by different methods

\begin{tabular}{lll}
\hline & $\begin{array}{l}\text { Strait of Gibraltar } \\
\text { (eastern part) }(\mathrm{km})\end{array}$ & $\begin{array}{l}\text { Kara Gates } \\
(\mathrm{km})\end{array}$ \\
\hline Calculated from dispersion relation & 94 & 48 \\
Calculated using the numerical model & 92 & 44 \\
\hline
\end{tabular}

in both directions from the sill. The perturbations of the density field induced by the propagating internal tide are shown in Fig. 10 after three tidal periods of calculation.

The fluctuations of the density field are not symmetrical with respect to the position of the sill. Due to the oppositely directed mean current, the barotropic tide induces a stronger internal tide propagating to the southwest (opposite to the mean current) compared to that propagating to the northeast. The wavelength in the southwestern direction is approximately equal to $44 \mathrm{~km}$, while in the northeastern direction, it is greater $(51 \mathrm{~km})$. This difference is caused by the current flowing from the Barents Sea. The leading edge of the wave is flat and the trailing edge is steep. At a small distance from the ridge, the internal bore is formed at the trailing edge. The isopycnals sharply deepen to $20 \mathrm{~m}$ forming a bore. A packet of short-period waves follows the bore. These smaller scale waves and the bore induce vertical motions, which manifest themselves at the surface. The bore is not formed in the wave propagating to northeast.

According to the model calculations, the wavelength of the wave propagating to southwest is $44 \mathrm{~km}$. This agrees with the calculations made on the basis of the dispersion relation. The wavelengths of the internal tide calculated using the numerical model and the estimates from the dispersion relation are given in Table 4. The introduction of the current from the Barents Sea intensifies the internal bore in the southwestern part of the strait. This is seen in a satellite image of the sea surface (see Section 5).

\section{Satellite observations}

Satellite photos of internal waves in the Strait of Gibraltar show that the surface manifestation of internal tides is clearly seen in the eastern part of the Strait of Gibraltar (Fig. 11a). Usually no manifestation of internal tides is seen in the western part of the strait. In the previous sections, we related this fact to the outflowing current from the Mediterranean Sea. This current has a greater influence on internal tide than the one from the ocean.

We observe a similar pattern of satellite image in the Strait of Kara Gates (Fig. 11b). In this case, the surface manifestation of internal tide is observed in the southwestern part of the strait. This agrees with the physical interpretation of surface manifestation of internal tide given for the Strait of Gibraltar. In the case of the Kara Gates, the current from the Kara Sea is located only in the deepest part of the strait. Hence it is not important for the internal tide. The northeastward flow from the Barents Sea is most important here. Therefore, the waves propagating to southwest are intensified by this flow. Their surface manifestation is stronger.

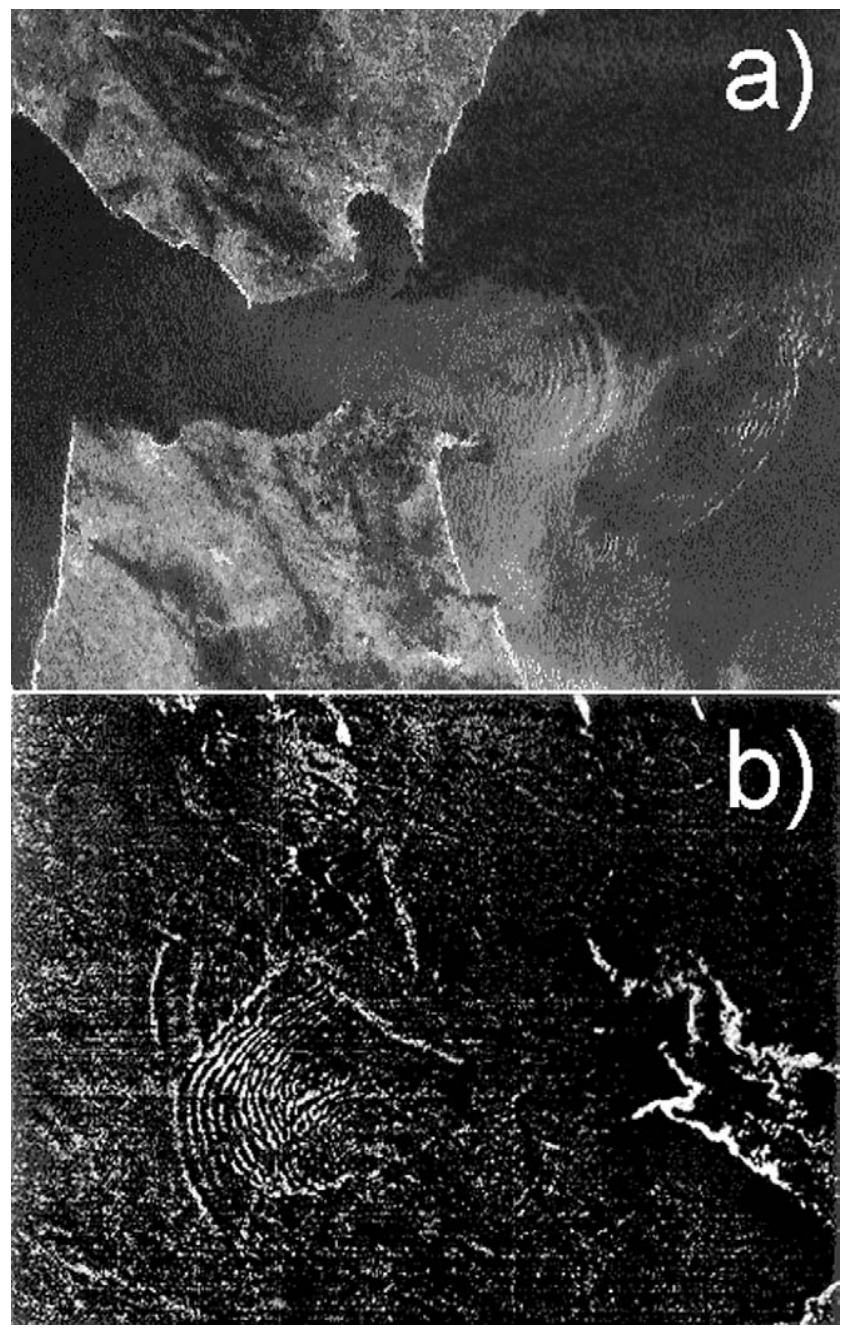

Fig. 11. Satellite photos of internal waves: (a) in the Strait of Gibraltar (NASA photograph 34-081, 1985) and (b) in the Kara Gates (Almaz satellite, 1991).

\section{Discussion}

The analysis of data from moorings in the Strait of Gibraltar and in the Strait of Kara Gates shows that internal tides in these straits have very large amplitude. The observations indicate that internal tides generated over the sills are very intense with vertical peak-to-peak displacements sometimes exceeding $200 \mathrm{~m}$ in the Strait of Gibraltar and $70 \mathrm{~m}$ in the Kara Gates. The waves propagate along the strait axis in a stratified flow, which changes their properties. Internal tides in both straits are induced by the same physical mechanism: the barotropic tide flowing over the sill. Strong mean currents in the straits is another common dynamical feature characteristic of both straits.

Internal tidal motion affects the entire water column. In the Strait of Gibraltar, the maximum of the first mode of internal tide is located in the outflowing current, therefore the interaction of the internal tide with the flow from the Mediterranean Sea is more important.

In the eastern part of the Strait of Gibraltar, the internal tide is intensified because its direction is opposite to the 
outflowing Mediterranean current. This interaction with the current shortens the wavelength and concentrates the wave energy at a smaller spatial scale and, hence, the wave amplitude increases. This leads to a non-linear transformation and breaking of the internal tide and formation of an undular internal bore on the trailing edge of the wave and intensive vertical motions, which manifest themselves at the sea surface. The packets of short-period internal waves, which follow the bore, are clearly seen at the surface. In addition, the pycnocline east of the sill, where the short-period waves develop, is raised close to the surface. West of the sill, the situation is opposite: the wave propagates in the same direction as the outflowing current. This increases the wavelength and reduces the amplitude of the wave. The pycnocline is deeper, and the bore is not so intense. The surface manifestation of internal waves is not so clear.

A similar phenomenon occurs in the Kara Gates. The amplitudes are maximal at the mid-depth. The current from the Barents Sea to the Kara Sea is observed in almost the entire water column excluding the deep channel located in the southeastern part of the strait, where the opposite current from the Kara Sea has been recorded. Almost all internal motion occurs in the flow from the Barents Sea.

In the southwestern part of the Strait of Kara Gates, the opposite direction of current and internal tide lead to the intensification of the latter. Intensive vertical motions are induced, which are associated with a packet of sort-period waves that follow the bore. The manifestation of these motions is observed at the sea surface. Short-period internal waves are clearly seen in the satellite radar image of the sea surface. In the northeastern part of the strait, the situation is opposite. The wave propagates in the same direction as the current from the Barents Sea. This causes an increase in the wavelength, hence the amplitude of the wave decreases and there seems to be no non-linear transformation.

The multi-layer numerical model used to calculate the generation and propagation of internal tides in the strait confirmed the observed properties of the internal tide. Modeling results show the formation of an undular bore east of the sill and a weak internal bore west of it. The values of wave parameters obtained in the model are in good agreement with the field observation. They also correlate with the observations of the spatial periodicity of the internal bore observed in the eastern part of the strait. The model with continuous stratification reproduces the properties of the internal tide and wave breaking better than the two-layer models. The model shows the important role of the outflowing current in forming the undular bore. A strong shear between oppositely directed currents intensifies the bore and wave packet in the upper layer.

\section{Conclusions}

Internal tidal oscillations observed in the Gibraltar and Kara Gates straits are generated over the sill due to the interaction with the barotropic tide.
The analysis of the available data yields that the internal tides have peak-to-peak amplitudes almost as large as the depth of the water column. These waves propagate in both directions from the sill losing energy while propagating. The major motion of the internal tide is associated with the semidiurnal M2 frequency.

Internal tides propagating in the opposite direction to the lower current in the Strait of Gibraltar and to the current from the Barents Sea in the Kara Gates are accompanied with an internal bore and packets of short-period waves, which can be identified at the surface. The internal bore is better manifested in the regions where it propagates opposite to the current. This bore and the accompanying packet of shorter internal waves are the main and evident surface indication of the internal tide. This phenomenon observed in two straits gives additional explanation as to why some of the observations, made mostly by remote observation of the surface, support the common perception that internal tides exist only in the eastern part of the Strait of Gibraltar.

The main difference between two regions is in their latitudinal position.

\section{Acknowledgements}

This research was supported by a sabbatical grant to E. Morozov given by Ministerio de Education Cultura y Deporte (Spain) (SAB2000-009), by the Ministerio de Ciencia y Tecnologia (Spain) under grant PB-96-599, spent at the Instituto Español de Oceanografía. This study was also supported by INTAS grant 01-0025. The data of moored measurements in Gibraltar were taken from the WOCE Current Meter Data Assembly Center in Oregon State University (USA). The authors thank V. Vlasenko for the numerical model used in the calculations. The authors also thank S. Erofeeva (Oregon State University, Corvallis, USA) for calculating the velocities of the barotropic tide in the Kara Gates Strait. The authors are grateful to A. Ivanov for providing them with the satellite photo of internal waves in the Kara Gates. Finally, the authors thank two anonymous referees for their useful comments, which were accepted.

\section{References}

Armi, L., Farmer, D.M., 1988. The flow of Mediterranean water through the Strait of Gibraltar, Farmer, D.M., and L. Armi, The flow of Atlantic water through the Strait of Gibraltar. Prog. Oceanogr. 21, 1-105.

Bryden, H.L., Candela, J., Kinder, T.H., 1994. Exchange through the Strait of Gibraltar. Prog. Oceanogr. 33, 201-248.

Brandt, P., Alpers, W., Backhaus, J.O., 1996. Study of the generation and propagation of internal waves in the Strait of Gibraltar using a numerical model and synthetic aperture radar images of the European ERS 1 satellite. J. Geophys. Res. C. 101, 14237-14252.

Furevik, T., Foldvik, A., 1996. Stability at M2 critical latitude in the Barents Sea. J. Geophys. Res. C. 101, 8823-8837.

Harms, I.H., Karcher, M.J., 1999. Modeling the seasonal variability of the hydrography and circulation in the Kara Sea. J. Geophys. Res. C. 104, 13431-13448. 
Hibia, T., 1990. Generation mechanism of internal waves by a vertically sheared tidal flow over a sill. J. Geophys. Res. C. 95, 1757-1764.

Jeans, D.R.G., Sherwin, T.I., 2001. The evolution and energetics of large amplitude waves on the Portuguese shelf. J. Mar. Res. 59, 327-353.

Johnson, D.R., McClimans, T.A., King, S., Grenness, Ø., 1997. Fresh water masses in the Kara Sea during summer. J. Mar. Syst. 12, 127-145.

Kinder, T.H., Bryden, H.L., 1987. The 1985-1986 Gibraltar experiment: data collection and preliminary results. EOS Trans. AGU 68, 786-787 and 793-795.

Lacombe, H., Richez, C., 1982. The regime of the Strait of Gibraltar. In: Nihoul, J.C.J. (Ed.), Hydrodynamics of Semi-Enclosed Seas. Elsevier, Amsterdam, pp. 13-74.

Longo, A., Manzo, M., Pierini, S., 1992. A model for the generation of non-linear internal tides in the Strait of Gibraltar. Oceanol. Acta 15, 233-243.

McClimans, T.A., Johnson, D.R., Krosshavn, M., King, S.E., Carrol, J., Grenness, Ø., 2000. Transport processes in the Kara. Sea. J. Geophys. Res. C. 105, 14121-14139.

Morozov, E.G., Trulsen, K., Velarde, M.G., Vlasenko, V.I., 2002. Internal tides in the Strait of Gibraltar. J. Phys. Oceanogr. 32, 3193-3206.

Oceanography from the Space Shuttle, 1989. NASA Photograph S-17-34-081. ONR 89.
Parks, T.W., Burrus, C.S., 1987. Digital Filter Design. John Wiley \& Sons, New York (Chapter 7, Section 7.3.3).

Pavlov, V.K., Pfirman, S.L., 1995. Hydrographic structure and variability of the Kara Sea: implications for pollutant distribution. Deep-Sea Res. 42, 1369-1390.

Richtmyer, R.D., 1957. Difference Methods for Initial-Value Problems. Interscience, New York 238 p.

Robertson, R., 2001. Internal tides and baroclinicity in the Southern Weddell Sea. 2. Effects of the critical latitude and stratification. J. Geophys. Res. C. 106, 27017-27034.

Vlasenko, V., Hutter, K., 2002. Numerical experiments on the breaking of solitary internal waves over a slope-shelf topography. J. Phys. Oceanogr. 32, 1779-1793.

Wang, D.P., 1993. The Strait of Gibraltar model: internal tide, diurnal inequality and fortnightly modulation. Deep-Sea Res. 40, 1187-1203.

Watson, G., 1994. Internal waves in a stratified shear flow: the Strait of Gibraltar. J. Phys. Oceanogr. 24, 509-517.

Xing, J., Davies, A.M., 1998. A three-dimensional model of internal tides on the Malin-Hebrides shelf and shelf edge. J. Geophys. Res. 103, 27821-27847. 